\title{
Risk of gallstones based on ABCG8 rs11887534 single nucleotide polymorphism among Taiwanese men and women
}

Keng-Wei Liang 1,2,4 , Hsin-Hui Huang 2,4, Lee Wang ${ }^{5}$, Wen-Yu Lu' ${ }^{5}$, Ying-Hsiang Chou 3,6, Disline Manli Tantoh 4,5, Oswald Ndi Nfor ${ }^{{ }^{*}}$, Neng-Yu Chiu ${ }^{4}$, Yeu-Sheng Tyan ${ }^{2,3,4}$ and Yung-Po Liaw ${ }^{4,5^{*}}$

\begin{abstract}
Background: Gallstones are abnormal masses caused by impaired metabolism of cholesterol, bilirubin, or bile salts in the gallbladder or biliary tract. ATP-binding cassette subfamily G member 8 (ABCG8) is a protein that regulates cholesterol efflux from the liver. Genome-wide association studies (GWAS) and meta-analyses of GWAS revealed the ABCG8 rs11887534 variant as the most common genetic determinant of gallstones in humans. These findings have not been extensively replicated in Taiwanese. Therefore, we appraised the relationship between gallstones and rs11887534 in a relatively large Taiwanese sample.
\end{abstract}

Methods: We retrieved data collected through questionnaires, physical and biochemical tests from the Taiwan Biobank Bank (TWB). The study participants comprised 7388 men and 13,880 women who voluntarily enrolled in the Taiwan Biobank project between 2008 and 2019. Gallstones were self-reported.

Results: The overall sample size was 21,268 comprising 938 gallstone patients and 20,330 non-gallstone individuals. Among the participants, 20,640 had the GG and 628 had the GC+ CC genotype. At $p$-value $<0.05$, the baseline genotypes and gallstone status between men and women were not significantly different. The risk of gallstones was higher in participants having the GC + CC compared to the GG genotype: odds ratio (OR); $95 \%$ confidence interval $(C l)=1.698 ; 1.240-2.325)$, but was lower in men compared to women $(\mathrm{OR}=0.763 ; 95 \% \mathrm{Cl}=0.638-0.913)$. Compared to men with the rs 11887534 GG genotype, women with the GG and GC + CC genotypes had a higher risk of gallstone (OR; $95 \% \mathrm{Cl}=1.304 ; 1.087-1.565$ for $\mathrm{GG}$ and 2.291; 1.514-3.467 for GC + CC). The positive association between GC + CC and gallstones was retained after we restricted the analysis to the female participants (OR; $95 \% \mathrm{Cl}=1.789=1.208-2.648)$. Hormone use was associated with an elevated risk of gallstones $(\mathrm{OR} ; 95 \% \mathrm{Cl}=1.359$; 1.107-1.668). Relative to $G G$ and no hormone use, we found a significantly high risk among hormone users with the $\mathrm{GC}+\mathrm{CC}$ genotype (OR; $95 \% \mathrm{Cl}=3.596 ; 1.495-8.650)$.

Conclusions: The rs11887534 GC + CC genotype was independently associated with a higher risk of gallstones. This risk was much higher among women, especially those who used hormones for various gynecological purposes.

Keywords: ABCG8, rs11887534, Dominant model, Gallstones, Hormone use

*Correspondence: nforoswald2@yahoo.com; Liawyp@csmu.edu.tw

${ }^{4}$ Department of Medical Imaging, Chung Shan Medical University Hospital, Taichung City 40201, Taiwan

${ }^{5}$ Department of Public Health and Institute of Public Health, Chung Shan Medical University, Taichung 40201, Taiwan

Full list of author information is available at the end of the article

\section{Introduction}

Gallstones are characterized by abnormal (solid, pebble-like) masses composed of excessive cholesterol, bilirubin, or bile salts in the gallbladder [1]. Gallstone disease, the most common biliary system disorder is 
a risk factor for gallbladder cancer which significantly contributes to health care burdens [1]. The burden of gallstone disease in Taiwan is increasing and so, the disease is becoming a public health concern in the country [2]. In Taiwan, the prevalence of gallstones was $4.3 \%$ in 1989 [3] and $10.7 \%$ in 1995 [4] implying a $6.4 \%$ difference within this time interval. Huang and his team conducted a nationwide study between 1997 and 2005 and reported a rise in the rate of hospitalization for severe gallstone disease [5]. A cross-sectional study in a rural community reported a $5 \%$ prevalence of gallstones between 2003 and 2004 [6] while a hospital-based study found a $7.6 \%$ prevalence in 2005 [7]. Furthermore, a cohort study conducted between 2002 and 2007 found a $0.632 \%$ yearly incidence of gallstones [8].

Gallstone disease is a multifactorial disorder, involving an interplay between genetic and non-genetic factors. Some risk factors are female sex, older age, higher BMI, and family history [2, 6, 8-10]. Exogenous female sex hormones which contain estrogens are key players in the etiology of gallstones [11, 12]. For instance, increased contraceptive use and hormone replacement therapy confer increased susceptibility to gallbladder diseases [11-16]. Twin and family studies reported about $25-29 \%$ genetic contribution to gallstones [17, 18]. ATP-binding cassette transporter (ABCG8) which regulates cholesterol efflux from the liver has been reported as the main genetic susceptibility factor for gallstones [17, 19-21].

The ABCG8 rs11887534 polymorphism (a G to C change), also called $\mathrm{D} 19 \mathrm{H}$, is a missense variation where the negatively charged amino acid, histidine, substitutes the positively charged aspartic acid [22]. GWAS found the ABCG8 rs11887534 variant as the most common genetic determinant in humans [22-25]. It is important to validate these findings in people of different ancestry because genetic association studies are population-specific. Numerous replication studies confirmed the role of rs11887534 in gallstone formation [7, 22, 26-30]. Moreover, several meta-analyses confirmed this variant as the most common genetic determinant in humans with different ancestries [22, 23, 31, 32]. To our knowledge, only one study underscored the impact of rs 11887534 on gallstone susceptibility among Taiwanese. However, only 979 individuals were included in the analysis [7]. A recent study recommended more research on rs11887534 polymorphism in relation to gallstones [21]. Moreover, the association between ABCG8 rs11887534 polymorphism according to sex has not been widely investigated. Taking into account the above concerns, we conducted this study to assess the risk of gallstones according to the ABCG8 rs11887534 polymorphism in a relatively large study sample involving Taiwanese men and women.

\section{Methods}

\section{Taiwan biobank}

We obtained data from the Taiwan biobank containing information on participants enrolled between 2008 and 2019. All the study participants met the eligibility criteria: strictly Taiwanese between aged 30 and 70 years with no prior cancer diagnosis. Each participant signed an informed consent letter before engaging in the data collection process, which was carried out in three phases: (1) self-responses to questionnaires (2) physical examination, and (3) biospecimen collection and examination [33]. We analyzed data from 21,268 participants (7388 men and 13,880 women) in the current study. Our work was approved by the Chung Shan Medical University Institutional Review Board (CS2-21005).

\section{ABCG8 rs11887534 genotyping}

SNPs were genotyped on the TWB1.0 and TWB2.0 custom chips and imputed using the IMPUTE2 (v2.3.1) software. Details on SNP genotyping and imputation in the Taiwan Biobank have been previously described [34]. Summarily, the TWB1.0 chip contains SNPs typed on the Axiom Genome-Wide CHB 1 Array plate (Affymetrix, Inc., Santa Clara, CA, USA). The chip contains about 650,000 SNPs for GWAS. The TWB2.0 SNP chip (Thermo Fisher Scientific, Inc., Santa Clara, CA, USA) can identify approximately 714,431 SNPs. For quality assurance, SNPs were excluded from the Biobank for the following reasons: (1) call rate $<0.98$, (2) heterozygosity rate $>5$ standard deviation (SD), (3) from third-degree relatives and (4) from non-East Asians. The ABCG8 rs11887534 SNP was used in this study because it met the quality control criteria stated above.

\section{Variable definition}

We obtained information on gallstone (yes/no), age, regular exercise (yes/no), cigarette smoking (yes/no), alcohol intake (yes/no), family history of gallstones (yes/ no), sex (men/women), diabetes (yes/no), dietary fat, menopause (yes/no), and hormone use (yes/no) from the self-responses of the participants to the Taiwan biobank questionnaires.

In the questionnaires, participants were asked if they had a personal history of clinically confirmed gallstones. Family history of gallstones was confirmed if the participants' father or mother has ever had gallstones. Hormone use was defined as the habit of using western hormonal medications to handle gynecological issues including menopause and contraception, among others for more than six months. In addition to self-reports, fasting glucose $>126 \mathrm{mg} / \mathrm{dL}$ or $\mathrm{HbA} 1 \mathrm{c} \geq 6.5 \%$ confirmed the presence of diabetes. Details on the other covariate (menopause, cigarette smoking, alcohol consumption, 
and regular exercise) assessments have been described elsewhere [35].

Body mass index (BMI) was grouped into four strata: normal BMI $\left(18.5 \leq \mathrm{BMI}<24 \mathrm{~kg} / \mathrm{m}^{2}\right)$, underweight $\left(\mathrm{BMI}<18.5 \mathrm{~kg} / \mathrm{m}^{2}\right)$, overweight $\left(24 \leq \mathrm{BMI}<27 \mathrm{~kg} / \mathrm{m}^{2}\right)$, and obesity $\left(B M I \geq 27 \mathrm{~kg} / \mathrm{m}^{2}\right)$ according to the Taiwan Health Promotion Administration. The dietary fat score was derived from a food frequency questionnaire containing seventeen questions related to the intake of fatrich foods in the previous month. The score was between 17 (low) and 85 (high) based on the sum of the responses to the 17 questions. The responses were ranked from 1-5: 1 (never), 2 (seldom), 3 (sometimes), 4 (frequently), and 5 (always). Levels of bilirubin, aspartate aminotransferase (AST), alanine transaminase (ALT), high-density lipoprotein cholesterol (HDL-C), low-density lipoprotein cholesterol (LDL-C), and triglyceride (TG) were determined at Chang Gung Memorial Hospital, Linkou, Taiwan using the Hitachi LST008 clinical analyzer (Tokyo, Japan).

\section{Statistical analysis}

We used SAS version 9.4 (SAS Institute, Cary, NC, USA) and Plink 1.9 for data analysis. Baseline statistics in the male and female participants were obtained using chisquared $(\mathrm{x} 2)$ and $\mathrm{t}$-tests. Specifically, the differences in categorical data between the male and female participants were determined with the $x^{2}$ test while the differences in continuous data were determined with the $t$-test. Categorical data were presented as $\mathrm{n}(\%)$ while continuous data were presented as mean \pm standard error (SE). A $p$-value $<0.05$ was set as the threshold for statistical significance. The association of gallstones with rs11887534 and other variables was determined by logistic regression analysis. The results were reported as odds ratios and $95 \%$ confidence intervals.

\section{Results}

Table 1 describes the baseline profiles of participants by sex (7388 men and 13,880 women). The participants comprised 938 gallstone patients and 20,330 non-gallstone individuals. Among the participants, 20,640 had the GG and 628 had the GC+CC genotype. At baseline, genotypes, gallstone status, and age were not significantly different between the male and female participants ( $p$-value $=0.1043,0.4880$, and 0.4702 , respectively $)$. The other variables were significantly different $(p<0.05)$ between men and women. Additional file 1: Table S1 shows the frequency of the GG, GC, and CC genotypes.

In the main effect model (Table 2), rs11887534 GC + CC compared to GG was associated with a higher risk of gallstone $(\mathrm{OR}=1.698 ; 95 \% \mathrm{CI}=1.240$ 2.325). Men had a lower risk of gallstones than women
$(\mathrm{OR}=0.763 ; \quad 95 \% \quad \mathrm{CI}=0.638-0.913)$. Other factors which were significantly associated with gallstones were age (OR; $95 \% \mathrm{CI}=1.050 ; 1.042-1.058)$, family history of gallstones (OR; $95 \% \mathrm{CI}=1.683 ; 1.360-2.083)$, total bilirubin (OR; 95\% CI=1.823; 1.464-2.269), AST (OR; 95\% CI =0.988; 0.977-0.998), ALT (OR; 95\% CI=1.011; 1.005-1.0117), and HDL-C (OR; 95\% CI $=0.985$; 0.9790.991). Additional file 1: Table $\mathrm{S} 2$ shows the risk of gallstones among individuals with the GC and CC genotypes compared to the GG genotype.

Table 3 shows the risk of gallstones according to the rs11887534 genotypes (GG and GC+CC) and sex. Compared to the reference group (men with the rs11887534 GG genotype), men with the GC+CC genotype had an elevated risk of gallstones but this observation did not achieve statistical significance $(\mathrm{OR}=1.598,95 \%$ $\mathrm{CI}=0.941-2.714)$. However, women carrying both the rs11887534 GG and GC+CC genotypes had a significantly higher risk of gallstones. Of note, the risk was higher among those with the GC+CC genotype. The OR; $95 \%$ CI was 1.304 ; $1.087-1.565$ for GG and 2.291; 1.514-3.467 for GC + CC. Age, family history, total bilirubin, AST, ALT, and HDL-C retained the significant relationship observed in the major effect model. The ORs; $95 \%$ CIs were $1.050 ; 1.042-1.058$ for age, 1.683; $1.360-2.083$ for family history of gallstones, $1.823 ; 1.464-$ 2.269 for total bilirubin, 0.988 ; $0.977-0.998$ for AST, $1.011 ; 1.005-1.0117$ for ALT, and $0.985 ; 0.979-0.991$ for HDL-C (Table 3). Additional file 1: Table S3 shows the risk of gallstones according to the rs11887534 genotypes (GG, GC, and CC) and sex.

Further analysis including only women while considering hormonal and menopausal status retained the positive association of the GC $+\mathrm{CC}$ genotype with gallstones: OR; $95 \% \mathrm{CI}=1.789=1.208-2.648$ (Table 4). Hormone use was associated with a higher risk of gallstones (OR; $95 \% \mathrm{CI}=1.359 ; 1.107-1.668)$. In this model, the previously observed relationship of gallstone with age, family history, total bilirubin, ALT, and HDL-C was retained. Exercise and overweight were respectively associated with a lower and higher risk of gallstones (OR; 95\% $\mathrm{CI}=0.816 ; 0.682-0.976$ for exercise and $1.307 ; 1.069$ 1.598 for overweight). Additional file 1: Table S4 shows the risk of gallstones among women with the GC and CC genotypes compared to the GG genotype.

Table 5 shows the risk of gallstones based on the combination of rs11887534 genotypes (GG and $\mathrm{GC}+\mathrm{CC})$ and hormone use. Compared to the reference group (rs11887534 GG and no hormone use), the risk of gout was significantly higher in all groups. The OR; 95\% CI was 1.333; 1.082-1.643 among hormone users with the GG genotype and 1.644; 1.0612.548 among non-hormone users with the $\mathrm{GC}+\mathrm{CC}$ 
Table 1 Baseline profiles of the study participants stratified by sex

\begin{tabular}{|c|c|c|c|}
\hline Variables & Women $(n=13,880)$ & Men $(n=7388)$ & $P$-value \\
\hline Gallstone & & & 0.1043 \\
\hline No & 13,291 (95.76) & $7039(95.28)$ & \\
\hline Yes & $589(4.24)$ & $349(4.72)$ & \\
\hline ABCG8 rs11887534 genotype & & & 0.4880 \\
\hline GG & $13,462(96.99)$ & $7178(97.16)$ & \\
\hline $\mathrm{GC}+\mathrm{CC}$ & $418(3.01)$ & $210(2.84)$ & \\
\hline Age (years) & $49.756 \pm 0.088$ & $49.868 \pm 0.128$ & 0.4702 \\
\hline Regular exercise & & & 0.0023 \\
\hline No & $8032(57.87)$ & $4115(55.70)$ & \\
\hline Yes & $5848(42.13)$ & $3273(44.30)$ & \\
\hline Cigarette smoking & & & $<.0001$ \\
\hline No & $13,272(95.62)$ & $4149(56.16)$ & \\
\hline Yes & $608(4.38)$ & $3239(43.84)$ & \\
\hline Alcohol drinking & & & $<.0001$ \\
\hline No & $13,571(97.77)$ & $5992(81.10)$ & \\
\hline Yes & $309(2.23)$ & $1396(18.90)$ & \\
\hline BMI $\left(\mathrm{kg} / \mathrm{m}^{2}\right)$ & & & $<.0001$ \\
\hline $18.5 \leq \mathrm{BMI}<24$ (Normal BMI) & $7944(57.23)$ & $2666(36.09)$ & \\
\hline BMI < 18.5 (Underweight) & $531(3.83)$ & $83(1.12)$ & \\
\hline $24 \leq \mathrm{BMI}<27$ (Overweight) & $3280(23.63)$ & $2698(36.52)$ & \\
\hline BMI $\geq 27$ (Obesity) & $2125(15.31)$ & $1941(26.27)$ & \\
\hline Family history of gallstones & & & 0.0153 \\
\hline No & $12,812(92.31)$ & $6887(93.22)$ & \\
\hline Yes & $1068(7.69)$ & $501(6.78)$ & \\
\hline Diabetes & & & $<.0001$ \\
\hline No & $12,759(91.92)$ & $6390(86.49)$ & \\
\hline Yes & $1121(8.08)$ & $998(13.51)$ & \\
\hline Total bilirubin (mg/dL) & $0.6138 \pm 0.002$ & $0.7516 \pm 0.004$ & $<.0001$ \\
\hline AST (U/L) & $23.1276 \pm 0.100$ & $26.2884 \pm 0.173$ & $<.0001$ \\
\hline $\mathrm{ALT}(\mathrm{U} / \mathrm{L})$ & $20.8680 \pm 0.147$ & $29.9571 \pm 0.274$ & $<.0001$ \\
\hline $\mathrm{HDL}-\mathrm{C}(\mathrm{mg} / \mathrm{dL})$ & $58.3463 \pm 0.113$ & $48.1481 \pm 0.131$ & $<.0001$ \\
\hline LDL-C (mg/dL) & $120.7000 \pm 0.271$ & $122.3000 \pm 0.368$ & 0.0003 \\
\hline $\mathrm{TG}(\mathrm{mg} / \mathrm{dL})$ & $102.3000 \pm 0.608$ & $137.000 \pm 1.288$ & $<.0001$ \\
\hline Dietary fat score & $41.7411 \pm 0.078$ & $45.9518 \pm 0.111$ & $<.0001$ \\
\hline \multicolumn{4}{|l|}{ Menopause } \\
\hline No & $6937(49.98)$ & - & - \\
\hline Yes & $6943(50.02)$ & - & - \\
\hline \multicolumn{4}{|l|}{ Hormone use } \\
\hline No & $11,721(84.45)$ & - & - \\
\hline Yes & $2159(15.55)$ & - & - \\
\hline
\end{tabular}

Continuous and categorical data are presented as mean \pm standard error (SE) and $\mathrm{n}$ (\%), respectively

$\mathrm{n}=$ sample size, $A B C G 8$ ATP-binding cassette subfamily $\mathrm{G}$ Member $8, B M I$ body mass index, $A S T$ aspartate aminotransferase, $A L T$ alanine transaminase, $H D L-C$ highdensity lipoprotein cholesterol, $L D L-C$ low-density lipoprotein cholesterol, $T G$ triglyceride

genotype. Remarkably, the highest odds ratio was observed in hormone users with the rs11887534 $\mathrm{GC}+\mathrm{CC}$ genotype (OR; $95 \% \mathrm{CI}=3.596 ; 1.495$ to 8.650). Age, exercise, overweight, family history, total bilirubin, ALT, and HDL remained significantly associated with gallstones. Additional file 1: Table S5 shows the risk of gallstones based on the combination of rs11887534 genotypes (GG, GC, and CC) and hormone use. 
Table 2 Association between the ABCG8 rs11887534 variant and gallstones in the study participants

\begin{tabular}{|c|c|c|c|c|}
\hline Variables & OR & \multicolumn{2}{|l|}{$95 \% \mathrm{Cl}$} & $P$-value \\
\hline \multicolumn{5}{|c|}{ ABCG8 rs11887534 genotype } \\
\hline GG (reference) & - & - & - & - \\
\hline $\mathrm{GC}+\mathrm{CC}$ & 1.698 & 1.240 & 2.325 & 0.0010 \\
\hline \multicolumn{5}{|l|}{ Sex } \\
\hline Women (reference) & - & - & - & - \\
\hline Men & 0.763 & 0.638 & 0.913 & 0.0032 \\
\hline Age & 1.050 & 1.042 & 1.058 & $<.0001$ \\
\hline \multicolumn{5}{|l|}{ Regular exercise } \\
\hline No (reference) & - & - & - & - \\
\hline Yes & 0.885 & 0.769 & 1.020 & 0.0914 \\
\hline \multicolumn{5}{|l|}{ Cigarette smoking } \\
\hline No (reference) & - & - & - & - \\
\hline Yes & 1.162 & 0.951 & 1.420 & 0.1430 \\
\hline \multicolumn{5}{|l|}{ Alcohol drinking } \\
\hline No (reference) & - & - & - & - \\
\hline Yes & 0.997 & 0.772 & 1.289 & 0.9839 \\
\hline \multicolumn{5}{|l|}{ BMl } \\
\hline Normal (reference) & - & - & - & - \\
\hline Underweight & 0.846 & 0.506 & 1.414 & 0.5238 \\
\hline Overweight & 1.158 & 0.987 & 1.359 & 0.0721 \\
\hline Obesity & 1.105 & 0.913 & 1.336 & 0.3052 \\
\hline \multicolumn{5}{|c|}{ Family history of gallstones } \\
\hline No (reference) & - & - & - & - \\
\hline Yes & 1.683 & 1.360 & 2.083 & $<.0001$ \\
\hline \multicolumn{5}{|l|}{ Diabetes } \\
\hline No (reference) & - & - & - & - \\
\hline Yes & 1.128 & 0.927 & 1.373 & 0.2302 \\
\hline Total bilirubin & 1.823 & 1.464 & 2.269 & $<.0001$ \\
\hline AST & 0.988 & 0.977 & 0.998 & 0.0214 \\
\hline ALT & 1.011 & 1.005 & 1.017 & 0.0004 \\
\hline $\mathrm{HDL}-\mathrm{C}(\mathrm{mg} / \mathrm{dL})$ & 0.985 & 0.979 & 0.991 & $<.0001$ \\
\hline LDL-C (mg/dL) & 0.998 & 0.996 & 1.000 & 0.1112 \\
\hline $\mathrm{TG}(\mathrm{mg} / \mathrm{dL})$ & 0.999 & 0.998 & 1.000 & 0.0593 \\
\hline Dietary fat score & 1.000 & 0.992 & 1.007 & 0.8992 \\
\hline
\end{tabular}

OR odds ratio, $C l$ confidence interval, $A B C G 8$ ATP-binding cassette subfamily $\mathrm{G}$ Member 8, BMI body mass index, AST aspartate aminotransferase, ALT alanine transaminase, $H D L-C$ high-density lipoprotein cholesterol, $L D L-C$ low-density lipoprotein cholesterol, TG triglyceride

\section{Discussion}

An in-depth understanding of population-specific risk factors, particularly genetic determinants of diseases, is important for the development of personalized preventive treatment options. In the present study, we assessed the association between gallstones and rs11887534 single nucleotide polymorphism, taking sex and hormone use into account. The $\mathrm{GC}+\mathrm{CC}$ genotype of the variant was significantly associated with a higher
Table 3 Association of the ABCG8 rs11887534 variant and sex with gallstones in the study participants

\begin{tabular}{|c|c|c|c|c|}
\hline \multirow{2}{*}{$\begin{array}{l}\text { Variables } \\
\text { ABCG8 rs } 11887534 \text { genotype, sex }\end{array}$} & \multirow[t]{2}{*}{ OR } & \multicolumn{2}{|c|}{$95 \% \mathrm{Cl}$} & \multirow[t]{2}{*}{$P$-value } \\
\hline & & & & \\
\hline $\begin{array}{l}\text { ABCG8 rs } 11887534 \text { GG, men (refer- } \\
\text { ence) }\end{array}$ & - & - & - & - \\
\hline ABCG8 rs11887534 GC+CC, men & 1.598 & 0.941 & 2.714 & 0.0827 \\
\hline ABCG8 rs11887534 GG, women & 1.304 & 1.087 & 1.565 & 0.0043 \\
\hline ABCG8 rs11887534 GC+CC, women & 2.291 & 1.514 & 3.467 & $<.0001$ \\
\hline Age & 1.050 & 1.042 & 1.058 & $<.0001$ \\
\hline \multicolumn{5}{|l|}{ Regular exercise } \\
\hline No (reference) & - & - & - & - \\
\hline Yes & 0.885 & 0.769 & 1.020 & 0.0918 \\
\hline \multicolumn{5}{|l|}{ Cigarette smoking } \\
\hline No (reference) & - & - & - & - \\
\hline Yes & 1.161 & 0.950 & 1.419 & 0.1448 \\
\hline \multicolumn{5}{|l|}{ Alcohol drinking } \\
\hline No (reference) & - & - & - & - \\
\hline Yes & 0.997 & 0.771 & 1.288 & 0.9798 \\
\hline \multicolumn{5}{|l|}{ BMl } \\
\hline Normal (reference) & - & - & - & - \\
\hline Underweight & 0.846 & 0.506 & 1.414 & 0.5239 \\
\hline Overweight & 1.159 & 0.987 & 1.360 & 0.0712 \\
\hline Obesity & 1.104 & 0.913 & 1.335 & 0.3057 \\
\hline \multicolumn{5}{|l|}{ Family history of gallstones } \\
\hline No (reference) & - & - & - & - \\
\hline Yes & 1.683 & 1.360 & 2.083 & $<.0001$ \\
\hline \multicolumn{5}{|l|}{ Diabetes } \\
\hline No (reference) & - & - & - & - \\
\hline Yes & 1.128 & 0.927 & 1.373 & 0.2302 \\
\hline Total bilirubin & 1.823 & 1.465 & 2.269 & $<.0001$ \\
\hline AST & 0.988 & 0.977 & 0.998 & 0.0213 \\
\hline ALT & 1.011 & 1.005 & 1.017 & 0.0004 \\
\hline $\mathrm{HDL}-\mathrm{C}(\mathrm{mg} / \mathrm{dL})$ & 0.985 & 0.979 & 0.991 & $<.0001$ \\
\hline LDL-C (mg/dL) & 0.998 & 0.996 & 1.000 & 0.1123 \\
\hline $\mathrm{TG}(\mathrm{mg} / \mathrm{dL})$ & 0.999 & 0.998 & 1.000 & 0.0592 \\
\hline Dietary fat score & 1.000 & 0.992 & 1.007 & 0.8959 \\
\hline
\end{tabular}

$O R$ odds ratio, $C l$ confidence interval, $A B C G 8$ ATP-binding cassette subfamily $\mathrm{G}$ Member 8, BMI body mass index, AST aspartate aminotransferase, ALT alanine transaminase, HDL-C high-density lipoprotein cholesterol, LDL-C low-density lipoprotein cholesterol, TG triglyceride

risk of gallstones, especially among women. Because sex appeared to play a role in the association between the genetic variant and gallstones, we restricted the analysis to female participants and considered menopausal status and hormone use. Hormone use was significantly associated with a higher risk of gallstones. Further analysis taking into consideration hormone use and genotype showed that female hormone users with the GC + CC genotype had the highest risk of gallstones. In general, age, family history, total bilirubin, 
Table 4 Association between the ABCG8 rs11887534 variant and gallstones in the female study participants

\begin{tabular}{|c|c|c|c|c|}
\hline Variables & OR & \multicolumn{2}{|c|}{$95 \% \mathrm{Cl}$} & $P$-value \\
\hline \multicolumn{5}{|c|}{ ABCG8 rs11887534 genotype } \\
\hline GG (reference) & - & - & - & - \\
\hline $\mathrm{GC}+\mathrm{CC}$ & 1.789 & 1.208 & 2.648 & 0.0037 \\
\hline \multicolumn{5}{|l|}{ Hormone use } \\
\hline No (reference) & - & - & - & - \\
\hline Yes & 1.359 & 1.107 & 1.668 & 0.0033 \\
\hline \multicolumn{5}{|l|}{ Menopause } \\
\hline No (reference) & - & - & - & - \\
\hline Yes & 1.250 & 0.934 & 1.672 & 0.1332 \\
\hline Age & 1.042 & 1.027 & 1.058 & $<.0001$ \\
\hline \multicolumn{5}{|l|}{ Regular exercise } \\
\hline No (reference) & - & - & - & - \\
\hline Yes & 0.816 & 0.682 & 0.976 & 0.0260 \\
\hline \multicolumn{5}{|l|}{ Cigarette smoking } \\
\hline No (reference) & - & - & - & - \\
\hline Yes & 1.243 & 0.827 & 1.869 & 0.2963 \\
\hline \multicolumn{5}{|l|}{ Alcohol drinking } \\
\hline No (reference) & - & - & - & - \\
\hline Yes & 1.317 & 0.786 & 2.205 & 0.2955 \\
\hline \multicolumn{5}{|l|}{ BMl } \\
\hline Normal (reference) & - & - & - & - \\
\hline Underweight & 0.900 & 0.518 & 1.565 & 0.7099 \\
\hline Overweight & 1.307 & 1.069 & 1.598 & 0.0090 \\
\hline Obesity & 1.189 & 0.931 & 1.520 & 0.1660 \\
\hline \multicolumn{5}{|c|}{ Family history of gallstones } \\
\hline No (reference) & - & - & - & - \\
\hline Yes & 1.730 & 1.332 & 2.246 & $<.0001$ \\
\hline \multicolumn{5}{|l|}{ Diabetes } \\
\hline No (reference) & - & - & - & - \\
\hline Yes & 1.054 & 0.805 & 1.380 & 0.6998 \\
\hline Total bilirubin & 1.875 & 1.348 & 2.606 & 0.0002 \\
\hline AST & 0.986 & 0.972 & 1.001 & 0.0709 \\
\hline ALT & 1.011 & 1.002 & 1.021 & 0.0215 \\
\hline $\mathrm{HDL}-\mathrm{C}(\mathrm{mg} / \mathrm{dL})$ & 0.988 & 0.981 & 0.996 & 0.0020 \\
\hline LDL-C (mg/dL) & 0.997 & 0.994 & 0.999 & 0.0125 \\
\hline $\mathrm{TG}(\mathrm{mg} / \mathrm{dL})$ & 1.000 & 0.999 & 1.001 & 0.7819 \\
\hline Dietary fat score & 1.005 & 0.995 & 1.014 & 0.3421 \\
\hline
\end{tabular}

$O R$ odds ratio, $C l$ confidence interval, $A B C G 8$ ATP-binding cassette subfamily $G$ Member 8, BMI body mass index, AST aspartate aminotransferase, $A L T$ alanine transaminase, $H D L-C$ high-density lipoprotein cholesterol, $L D L-C$ low-density lipoprotein cholesterol, TG triglyceride

ALT, and HDL each had a significant association with gallstones irrespective of sex and hormone use habit.

The ABCG8 gene is highly expressed in gallbladder epithelial cells [36]. Genetic variation in this gene is associated with cardiovascular disease, gallstones, and cancer of the biliary tract $[17,19,20,28,37-39]$. The role of rs11887534, the most common genetic determinant for gallstone predisposition is well-evidenced from GWAS [22, 23] and several replication studies [7, 22, 26-30]. Replication studies involving Germans, Chileans, Chinese, Danish, Indians, African and Hispanic Americans all showed significant associations between rs11887534 and gallstones [22, 31, 40]. However, in a study involving Mexican Americans and non-Hispanic blacks and whites, significant associations were observed only among nonHispanic whites. The non-significant results among Mexican Americans and non-Hispanic blacks were probably due to smaller sample sizes; 1705 Mexican Americans (227 cases and 1478 controls) and 1719 non-Hispanic blacks (179 cases and 1540) compared to 2408 Hispanic whites comprising 446 cases and 1962 controls [10].

Although several studies have been conducted on gallstones in Taiwan, only a few of them considered the role of the ABCG8 variant. In one study, Taiwanese with the GC genotype had higher levels of cholesterol and LDL [41]. In another study, the genotype was associated with a higher risk of gallstones [7]. The current study with a relatively large sample size further confirms the role of ABCG8 in gallstone predisposition among Taiwanese.

In mice and humans, this polymorphism promoted gallstone formation by increasing the expression of ABCG8, consequently enhancing biliary cholesterol production and buildup while decreasing dietary cholesterol absorption [40, 42, 43]. The decrease in dietary cholesterol absorption could be compensated for by high hepatic cholesterol synthesis leading to cholesterolsupersaturated bile.

Gallstone is predominant in women than men $[8,9,12$, 27, 44-46]. Exogenous female sex hormones are among the key players in the etiology of gallstones in women $[11,12]$. One pathological mechanism is that female sex hormones alter cholesterol metabolism and gallbladder/ intestinal motility. That is, they increase biliary cholesterol and alter bile composition, thereby impairing gallbladder motility [47]. In the liver, hormone replacement therapy, as well as the $17 \beta$-estradiol binding to estrogen receptors, promotes the release and saturation of cholesterol in bile $[48,49]$.

In a study among Chinese, the rs11887534 GC variant was associated with a higher probability of bladder cancer in both men and women, but significant results were prominent only among women [28]. Similarly, in a study among Indians, the association of gallstone with the ABCG8 rs11887534 polymorphism was more prominent in women [38]. The observation was attributed to hormone use [38]. In the current study, hormone use was associated with a higher risk of gallstones. Consistently, several studies reported a higher risk of gallbladder diseases with higher contraceptive use and hormone use [12-16, 46, 50-53]. Considering both sex and genotype 
Table 5 Association of the ABCG8 rs1 1887534 variant and hormone use with gallstones in the female study participants

\begin{tabular}{|c|c|c|c|c|}
\hline Variables & OR & $95 \% \mathrm{Cl}$ & & $P$-value \\
\hline \multicolumn{5}{|l|}{ ABCG8 rs11887534 genotype, hormone use } \\
\hline ABCG8 rs1 1887534 GG, no hormone use (reference) & - & - & - & - \\
\hline ABCG8 rs11887534 GG, hormone use & 1.333 & 1.082 & 1.643 & 0.0069 \\
\hline ABCG8 rs11887534 GC + CC, no hormone use & 1.644 & 1.061 & 2.548 & 0.0261 \\
\hline ABCG8 rs11887534 GC+CC, hormone use & 3.596 & 1.495 & 8.650 & 0.0043 \\
\hline \multicolumn{5}{|l|}{ Menopause } \\
\hline No (reference) & - & - & - & - \\
\hline Yes & 1.251 & 0.935 & 1.674 & 0.1312 \\
\hline Age & 1.042 & 1.027 & 1.058 & $<.0001$ \\
\hline \multicolumn{5}{|l|}{ Regular exercise } \\
\hline No (reference) & - & - & - & - \\
\hline Yes & 0.816 & 0.682 & 0.975 & 0.0256 \\
\hline \multicolumn{5}{|l|}{ Cigarette smoking } \\
\hline No (reference) & - & - & - & - \\
\hline Yes & 1.237 & 0.823 & 1.861 & 0.3068 \\
\hline \multicolumn{5}{|l|}{ Alcohol drinking } \\
\hline No (reference) & - & - & - & - \\
\hline Yes & 1.322 & 0.790 & 2.214 & 0.2885 \\
\hline \multicolumn{5}{|l|}{ BMl } \\
\hline Normal (reference) & - & - & - & - \\
\hline Underweight & 0.900 & 0.518 & 1.564 & 0.7084 \\
\hline Overweight & 1.312 & 1.073 & 1.605 & 0.0081 \\
\hline Obesity & 1.189 & 0.930 & 1.519 & 0.1667 \\
\hline \multicolumn{5}{|l|}{ Family history of gallstones } \\
\hline No (reference) & - & - & - & - \\
\hline Yes & 1.733 & 1.334 & 2.251 & $<.0001$ \\
\hline \multicolumn{5}{|l|}{ Diabetes } \\
\hline No (reference) & - & - & - & - \\
\hline Yes & 1.052 & 0.804 & 1.378 & 0.7115 \\
\hline Total bilirubin & 1.884 & 1.355 & 2.619 & 0.0002 \\
\hline AST & 0.986 & 0.972 & 1.001 & 0.0710 \\
\hline ALT & 1.011 & 1.002 & 1.021 & 0.0214 \\
\hline $\mathrm{HDL}-\mathrm{C}(\mathrm{mg} / \mathrm{dL})$ & 0.988 & 0.981 & 0.996 & 0.0019 \\
\hline LDL-C (mg/dL) & 0.997 & 0.994 & 0.999 & 0.0120 \\
\hline TG (mg/dL) & 1.000 & 0.999 & 1.001 & 0.7689 \\
\hline Dietary fat score & 1.005 & 0.995 & 1.014 & 0.3356 \\
\hline
\end{tabular}

OR odds ratio, $C l$ confidence interval, $A B C G 8$ ATP-binding cassette subfamily $G$ Member 8, BMI body mass index, AST aspartate aminotransferase, ALT alanine transaminase, $H D L-C$ high-density lipoprotein cholesterol, $L D L-C$ low-density lipoprotein cholesterol, $T G$ triglyceride

in the current study, we found no significant risk of gallstone in men irrespective of the genotype. Interestingly, the highest OR for gallstone was reported among female hormone users carrying the $\mathrm{GC}+\mathrm{CC}$ genotype. These results imply that the role of rs11887534 in gallstones might be more prominent in women with the strongest effect in hormone users, further confirming the role of hormone use in gallstone etiology.

Age and BMI are also independent determinants of gallstones $[6,8,9,27,45,46,52-58]$. Other reported risk factors for gallstones are family history [6], abnormal liver function tests including high bilirubin, AST, and ALT [54-56, 59], and abnormal lipoprotein levels including low HDL-C, high LDL-C, and triglycerides [46, 58, 60]. In the current study, age, family history, total bilirubin, AST, ALT, and HDL-C HDL were consistently associated with the risk of gallstone. Even though BMI was a risk factor, its association with gallstone was prominent only when we restricted the analysis to only female participants. Regular exercise was not significantly associated 
with the risk of gallstones in the general participants, but a sub-analysis involving only women showed a significant inverse association. This observation has been previously reported in both men and women [53, 61, 62] and women $[57,63]$.

As a strength, this nationwide population study among Taiwanese adults included 21,268 individuals (938 cases and 20,330 controls). This is a very large sample size compared to several studies. For instance, the only study in Taiwan that assessed the association between gallstones and rs 11887534 polymorphism had only 979 participants [7]. Moreover, a study replicating the association of gallstones with $11,887,534$ included only 334 Chileans (167 cases and 167 controls) and 1470 Germans comprising 728 cases and 732 controls [22]. Another replication study included only 2408 non-Hispanic whites, 1705 Mexican Americans, and 1719 non-Hispanic blacks [10]. In another study, there were 1122 Chileans (680 cases and 442 controls), 1132 Danish (366 cases and 766 controls), 471 Indians (247 cases and 224 controls), and 524 Chinese (280 cases and 244 controls [40].

As a limitation, gallstone information in this study was obtained through questionnaires which could have increased the probability of information bias. Moreover, we did not stratify the participants based on the specific purpose for which they used hormones. Hence, the use of oral contraceptives and hormone replacement therapy were all considered as hormone use.

\section{Conclusions}

The $\mathrm{GC}+\mathrm{CC}$ genotype was independently associated with a higher risk of gallstones. Having the genotype and being a female participant was associated with a much-elevated risk. Hormone use among women with the $\mathrm{GC}+\mathrm{CC}$ genotype was also associated with a much higher risk. This suggests that genetic factors and female hormones are very substantial in the etiology of gallstones and a combination of both factors could exacerbate the disease risk.

\section{Supplementary Information}

The online version contains supplementary material available at https://doi. org/10.1186/s12876-021-02060-5.

Additional file 1. Table S1. Baseline profiles of participants stratified by sex showing the frequency of the GG, GC, and CC genotypes. Table S2. Risk of gallstones among individuals with the GC and CC genotypes compared to the GG genotype. Table S3. Risk of gallstones according to the rs11887534 genotypes (GG, GC, and CC) and sex. Table S4. Risk of gallstones among women with the GC and CC genotypes compared to the GG genotype. Table S5. Risk of gallstones based on the combination of rs 11887534 genotypes (GG, GC, and CC) and hormone use.

\section{Acknowledgements}

We thank the Ministry of Science and Technology and Chung Shan Medical University for the financial support.

\section{Authors' contributions}

Conceptualization and design, $\mathrm{K}-\mathrm{WL}, \mathrm{H}-\mathrm{HH}, \mathrm{LW}, \mathrm{W}-\mathrm{YL}, \mathrm{Y}-\mathrm{HC}, \mathrm{DMT}, \mathrm{ONN}, \mathrm{N}-\mathrm{YC}$, Y-ST, Y-PL; methodology, W-YL, N-YC, Y-ST, Y-HC; resources, Y-PL; data curation, LW, W-YL; writing - original draft preparation, K-WL, DMT; statistical analysis, W-YL, Y-PL, ONN, H-HH; writing - review and editing, $\mathrm{H}-\mathrm{HL}$, LW, ONN, Y-HC, $\mathrm{N}-\mathrm{YC}, \mathrm{Y}-\mathrm{ST}$; supervision, $\mathrm{Y}-\mathrm{PL}, \mathrm{ONN}$. All authors read and approved the final manuscript.

\section{Funding}

We acknowledge the Chung Shan Medical University Hospital (CSH2021-C-032) and the Ministry of Science and Technology (MOST), Taiwan (MOST 109-2121-M-040-002; MOST 110-2121-M-040-002) for their financial support.

\section{Availability of data and materials}

The data that support the findings of this study are available from Taiwan Biobank but restrictions apply to the availability of these data, which were used under license for the current study, and so are not publicly available. Data are however available from the authors upon reasonable request and with permission of Taiwan Biobank.

\section{Declarations}

\section{Ethics approval and consent to participate}

This study was approved by the Institutional Review Board of Chung Shan Medical University (CS2-21005). Taiwan Biobank participants had provided written informed consent during enrollment. All methods were performed in accordance with the relevant guidelines and regulations.

\section{Consent for publication}

Not applicable.

\section{Competing interests}

The authors declare that they have no competing interests.

\section{Author details}

${ }^{1}$ Institute of Medicine, Chung Shan Medical University, Taichung City 40201, Taiwan. ${ }^{2}$ School of Medicine, Chung Shan Medical University, Taichung 40201, Taiwan. ${ }^{3}$ Department of Medical Imaging and Radiological Sciences, Chung Shan Medical University, Taichung 40201, Taiwan. ${ }^{4}$ Department of Medical Imaging, Chung Shan Medical University Hospital, Taichung City 40201, Taiwan. ${ }^{5}$ Department of Public Health and Institute of Public Health, Chung Shan Medical University, Taichung 40201, Taiwan. ${ }^{6}$ Department of Radiation Oncology, Chung Shan Medical University, Taichung 40201, Taiwan.

Received: 31 July 2021 Accepted: 2 December 2021

Published online: 14 December 2021

References

1. Reshetnyak VI. Concept of the pathogenesis and treatment of cholelithiasis. World J Hepatol. 2012;4(2):18.

2. Hung $\mathrm{S}-\mathrm{C}$, et al. Risk factors associated with symptomatic cholelithiasis in Taiwan: a population-based study. BMC Gastroenterol. 2011;11(1):1-7.

3. Lu S-N, et al. Risk factors for gallstones among Chinese in Taiwan. A community sonographic survey. J Clin Gastroenterol. 1990;12(5):542-6.

4. Chen C-Y, et al. Age is one of the risk factors in developing gallstone disease in Taiwan. Age Ageing. 1998;27(4):437-41.

5. Huang J, et al. Nationwide epidemiological study of severe gallstone disease in Taiwan. BMC Gastroenterol. 2009;9(1):1-10.

6. Chen $\mathrm{CH}$, et al. Prevalence and risk factors of gallstone disease in an adult population of Taiwan: an epidemiological survey. J Gastroenterol Hepatol. 2006:21(11):1737-43.

7. Kuo K, et al. Significant association of ABCG5 604Q and ABCG8 D19H polymorphisms with gallstone disease. J Br Surg. 2008;95(8):1005-11. 
8. Chen J-Y, et al. Clinical predictors of incident gallstone disease in a Chinese population in Taipei, Taiwan. BMC Gastroenterol. 2014;14(1):1-7.

9. Liu C-M, et al. Clinical correlation of gallstone disease in a Chinese population in Taiwan: experience at Cheng Hsin General Hospital. World J Gastroenterol WJG. 2006;12(8):1281.

10. Goodloe R, et al. Lipid trait-associated genetic variation is associated with gallstone disease in the diverse Third National Health and Nutrition Examination Survey (NHANES III). BMC Med Genet. 2013;14(1):1-9.

11. Dhiman RK, Chawla YK. Is there a link between oestrogen therapy and gallbladder disease? Expert Opin Drug Saf. 2006;5(1):117-29.

12. Novacek G. Gender and gallstone disease. Wien Med Wochenschr. 2006;156(19):527-33.

13. Dhiman RK, Chawla YK. Hormone replacement therapy and gallstone disease: a real association. Digestion. 2008;77(1):1.

14. Cirillo DJ, et al. Effect of estrogen therapy on gallbladder disease. JAMA. 2005:293(3):330-9.

15. Hart AR, et al. Hormone replacement therapy and symptomatic gallstones-a prospective population study in the EPIC-Norfolk cohort. Digestion. 2008;77(1):4-9.

16. Sieron $D$, et al. The effect of chronic estrogen application on bile and gallstone composition in women with cholelithiasis. Minerva Endocrinol. 2014;41(1):19-27.

17. Katsika D, et al. Gallstone disease in Swedish twins: risk is associated with ABCG8 D19H genotype. J Intern Med. 2010;268(3):279-85.

18. Nakeeb A, et al. Gallstones: genetics versus environment. Ann Surg. 2002;235(6):842.

19. Grünhage $F$, et al. Increased gallstone risk in humans conferred by common variant of hepatic ATP-binding cassette transporter for cholesterol. Hepatology. 2007;46(3):793-801.

20. Wang Y, et al. ATP binding cassette G8 T400K polymorphism may affect the risk of gallstone disease among Chinese males. Clin Chim Acta. 2007;384(1-2):80-5.

21. Rebholz C, Krawczyk M, Lammert F. Genetics of gallstone disease. Eur J Clin Investig. 2018;48(7):e12935.

22. Buch S, et al. A genome-wide association scan identifies the hepatic cholesterol transporter ABCG8 as a susceptibility factor for human gallstone disease. Nat Genet. 2007;39(8):995-9.

23. Chauhan T, Mittal R, Mittal B. Association of common single nucleotide polymorphisms of candidate genes with gallstone disease: a metaanalysis. Indian J Clin Biochem. 2020;35(3):290-311.

24. Ferkingstad $\mathrm{E}$, et al. Genome-wide association meta-analysis yields 20 loci associated with gallstone disease. Nat Commun. 2018:9(1):1-11.

25. Gellert-Kristensen $\mathrm{H}$, et al. Identification and replication of six loci associated with gallstone disease. Hepatology. 2019;70(2):597-609.

26. Siddapuram SP, et al. Hepatic cholesterol transporter ABCG8 polymorphisms in gallstone disease in an Indian population. J Gastroenterol Hepatol. 2010;25(6):1093-8.

27. Stender $\mathrm{S}$, et al. Sterol transporter adenosine triphosphate-binding cassette transporter G8, gallstones, and biliary cancer in 62,000 individuals from the general population. Hepatology. 2011;53(2):640-8.

28. $\mathrm{Xu} \mathrm{H-L}$, et al. Cholesterol metabolism gene polymorphisms and the risk of biliary tract cancers and stones: a population-based case-control study in Shanghai, China. Carcinogenesis. 2011;32(1):58-62.

29. Renner $\mathrm{O}$, et al. Role of the $\mathrm{ABCG} 819 \mathrm{H}$ risk allele in cholesterol absorption and gallstone disease. BMC Gastroenterol. 2013;13(1):1-11.

30. Zhan $L$, et al. Prevalence of $A B C B 4$ polymorphisms in gallstone disease in han-Chinese population. Am J Transl Res. 2016;8(2):1218

31. Joshi AD, et al. Four susceptibility loci for gallstone disease identified in a meta-analysis of genome-wide association studies. Gastroenterology. 2016:151(2):351-363. e28

32. Jiang Z-Y, Cai $Q$, Chen E-Z. Association of three common single nucleotide polymorphisms of ATP binding cassette G8 gene with gallstone disease: a meta-analysis. PLoS ONE. 2014;9(1):e87200.

33. Biobank, T. Taiwan Biobank. 2015 [cited 2021 November 1]: Participation program]. Available from: https://www.twbiobank.org.tw/new_ web en/join-flow-before.php.

34. Wei C-Y, et al. Genetic profiles of 103,106 individuals in the Taiwan Biobank provide insights into the health and history of Han Chinese. NPJ Genom Med. 2021;6(1):1-10.
35. Hsu T-L, et al. Association between osteoporosis and menopause in relation to SOX6 rs 297325 variant in Taiwanese women. Menopause (New York, NY). 2020;27(8):887.

36. Tauscher A, Kuver R. ABCG5 and ABCG8 are expressed in gallbladder epithelial cells. Biochem Biophys Res Commun. 2003;307(4):1021-8.

37. Besseling J, et al. Severe heterozygous familial hypercholesterolemia and risk for cardiovascular disease: a study of a cohort of 14,000 mutation carriers. Atherosclerosis. 2014;233(1):219-23.

38. Srivastava A, et al. Effect of genetic variant (rs1 1887534) in ABCG8 gene in coronary artery disease and response to atorvastatin therapy. Dis Markers. 2010;28(5):307-13.

39. Srivastava A, et al. Single nucleotide polymorphism in the ABCG8 transporter gene is associated with gallbladder cancer susceptibility. Liver Int. 2009;29(6):831-7.

40. Von Kampen O, et al. Genetic and functional identification of the likely causative variant for cholesterol gallstone disease at the ABCG5/8 lithogenic locus. Hepatology. 2013;57(6):2407-17.

41. Chen Z-C, et al. Significant association of ABCG8: D19H gene polymorphism with hypercholesterolemia and insulin resistance. J Hum Genet. 2008;53(8):757-63.

42. Yu L, et al. Overexpression of ABCG5 and ABCG8 promotes biliary cholesterol secretion and reduces fractional absorption of dietary cholesterol. J Clin Investig. 2002;110(5):671-80.

43. Wittenburg $\mathrm{H}$, et al. Association of a lithogenic Abcg5/Abcg8 allele on Chromosome 17 (Lith9) with cholesterol gallstone formation in PERA/ EiJ mice. Mamm Genome. 2005;16(7):495-504.

44. Shaffer EA. Epidemiology of gallbladder stone disease. Best Pract Res Clin Gastroenterol. 2006;20(6):981-96.

45. Shabanzadeh DM. New determinants for gallstone disease. Dan Med J. 2018;65(2):B5438

46. Shabanzadeh DM, Sørensen LT, Jørgensen T. Determinants for gallstone formation-a new data cohort study and a systematic review with meta-analysis. Scand J Gastroenterol. 2016;51(10):1239-48.

47. Chen Y, Kong J, Wu S. Cholesterol gallstone disease: focusing on the role of gallbladder. Lab Invest. 2015;95(2):124-31.

48. Wang $\mathrm{HH}$ et al., New insights into the molecular mechanisms underlying effects of estrogen on cholesterol gallstone formation. Biochimica et Biophysica Acta (BBA)-Molecular and Cell Biology of Lipids, 2009. 1791(11): 1037-47.

49. Uhler ML, et al. Comparison of the impact of transdermal versus oral estrogens on biliary markers of gallstone formation in postmenopausal women. J Clin Endocrinol Metab. 1998:83(2):410-4.

50. Racine A, et al. Menopausal hormone therapy and risk of cholecystectomy: a prospective study based on the French E3N cohort. CMAJ. 2013;185(7):555-61.

51. Nordenvall C, et al. Postmenopausal hormone replacement therapy and risk of cholecystectomy: a prospective cohort study. Scand J Gastroenterol. 2013;49(1):109-13.

52. Shabanzadeh DM, et al. Are incident gallstones associated to sex-dependent changes with age? A cohort study. Andrology. 2017:5(5):931-8.

53. Figueiredo JC, et al. Sex and ethnic/racial-specific risk factors for gallbladder disease. BMC Gastroenterol. 2017:17(1):1-12.

54. Liew P-L, et al. Gallbladder disease among obese patients in Taiwan. Obes Surg. 2007;17(3):383-90.

55. Liu C-M, et al. A community-based epidemiologic study on gallstone disease among type 2 diabetics in Kinmen, Taiwan. Dig Dis. 2004;22(1):87-91.

56. Tung $\mathrm{T}-\mathrm{H}$, et al. A population-based follow-up study on gallstone disease among type 2 diabetics in Kinmen, Taiwan. World I Gastroenterol WJG. 2006;12(28):4536.

57. Hou L, et al. Anthropometric measurements, physical activity, and the risk of symptomatic gallstone disease in Chinese women. Ann Epidemiol. 2009:19(5):344-50.

58. Festi $\mathrm{D}$, et al. Incidence of gallstone disease in Italy: results from a multicenter, population-based Italian study (the MICOL project). World J Gastroenterol WJG. 2008;14(34):5282.

59. Videhult $P$, et al. Are liver function tests, pancreatitis and cholecystitis predictors of common bile duct stones? Results of a prospective, population-based, cohort study of 1171 patients undergoing cholecystectomy. HPB. 2011;13(8):519-27. 
60. Wang J, et al. Serum lipid levels are the risk factors of gallbladder stones: a population-based study in China. Lipids Health Dis. 2020;19(1):1-6.

61. Chuang CZ, et al. Physical activity, biliary lipids, and gallstones in obese subjects. Am J Gastroenterol. 2001;96(6):1860-5.

62. Shabanzadeh DM, Sørensen LT, Jørgensen T. Determinants for clinical events in gallstone carriers unaware of their gallstones. J Gastroenterol Hepatol. 2017;32(3):721-6.

63. Storti KL, et al. Physical activity and decreased risk of clinical gallstone disease among post-menopausal women. Prev Med. 2005;41(3-4):772-7.

\section{Publisher's Note}

Springer Nature remains neutral with regard to jurisdictional claims in published maps and institutional affiliations.

- fast, convenient online submission

- thorough peer review by experienced researchers in your field

- rapid publication on acceptance

- support for research data, including large and complex data types

- gold Open Access which fosters wider collaboration and increased citations

- maximum visibility for your research: over $100 \mathrm{M}$ website views per year

At $\mathrm{BMC}$, research is always in progress.

Learn more biomedcentral.com/submissions 